\title{
THE ROLE OF WATER ACTIVITY IN TERMS OF ENZYME ACTIVITY AND ENANTIOSELECTIVITY DURING ENZYMATIC ESTERIFICATION IN NON- CONVENTIONAL MEDIA
}

\author{
PIROSKA LAJTAI-SZABÓ ${ }^{1}$, NÁNdOR NEMESTÓthY ${ }^{1}$, AND LÁSZló GuBICZA *1 \\ ${ }^{1}$ Research Institute on Bioengineering, Membrane Technology and Energetics, University of Pannonia, \\ Egyetem u. 10, Veszprém, 8200, HUNGARY
}

\begin{abstract}
During enzymatic esterification in non-conventional media, the activity and enantioselectivity of the enzyme is significantly influenced by the water content of the reaction medium, which continuously changes as water is produced during the esterification. To provide constant reaction parameters, water activity should be kept constant. The commonly used salt hydrate pairs may be difficult to apply and often hinder enzyme activity. During the enantioselective esterification of racemic 2-bromopropanoic acid in various solvents (organic solvents, ionic liquids), it was proven that the conditions related to the optimal water content required for kinetic examinations can be provided without using any salt or salt hydrate pairs. This conclusion is based on the realization that the optimal water activity can be set by first determining the initial water content that is necessary to achieve the maximum reaction rate in the given solvent.
\end{abstract}

Keywords: enzymatic enantioselective esterification, non-conventional media, ionic liquid, racemic acid, effect of water content

\section{Introduction}

The history of the intentional use of enzymes as biocatalysts stretches back several decades. In recent years, intensified interest has been shown in applying enzymes in chemical reactions. Enzyme technology as an important discipline of biotechnology has begun to develop rapidly. Nowadays, it is of great importance in the pharmaceutical and pesticide industries where, in many cases, it has produced intermediates and active substances with enzymes or microorganisms more easily than by chemical synthesis and usually with a high degree of (enantio)selectivity [1-3].

The known advantages of these reactions are the mild reaction conditions, pure products, high yield and, in many cases, environmentally friendly by-products. At first, enzymes were only applied in aqueous media as they exert their catalytic activity under such conditions in various organisms. Later, the recognition that enzymes can exert their catalytic activity in organic solvents promoted intensive investigation among organic chemists who tested more and more enzymes from various classes as catalysts of organic chemical reactions [1,4-7].

Contradictory results concerning how the activity and enantioselectivity of a lipase depend on the physical and chemical properties of the solvents can be found in the literature. In some cases, the different enzyme activities and

\footnotetext{
*Correspondence: gubiczal@almos.uni-pannon.hu
}

enantioselectivities observed in various organic solvents are not only affected by the solvents, e.g., when solvents with very different polarities are compared without fixing the water activity. In these experiments, the variation in the water activity probably contributes to the change in enzyme activity [6,8-10].

In terms of the reaction, the water content of the reaction medium is twice as significant. To keep the enzyme activity and enantioselectivity of the lipase constant, a constant amount of water should be provided. As the content of the reaction medium changes as the conversion proceeds, the water adsorption capacity of the reaction medium does not remain constant during the reaction either. Water activity is an index which indicates how much water is accessible to the enzyme. Polar solvents can adsorb more water, while in non-polar solvents less water is required to achieve saturation and form a new aqueous phase where the water activity of the organic solvent is equal to one $\left(a_{\mathrm{w}}=1\right)$. Therefore, two solvents of different polarities but equal water activities may contain significantly different amounts of water [11-13].

Based on the aforementioned considerations, in the literature a constant water activity is sought instead of a constant concentration of water during enzymatic reactions, e.g. by pervaporation of salt hydrates [14-16]. In reactions where water is not produced, the initial water activity of the reaction medium is fixed and the change in water activity, which is caused by changes in the polarity 
of the reaction medium, is neglected. In the case of esterifications, where the water activity of the reaction medium significantly increases as the reaction proceeds, the water activity must be constantly controlled [16-19].

In this study, the resolution of $(R, S)-2-$ bromopropanoic acid was analyzed. Changes in the activity and enantioselectivity of the enzyme Candida rugosa lipase, which is suitable when the water content of the reaction medium is changed during the aforementioned reaction, were investigated. Identification of the simplest method to sustain a constant water activity required for kinetic examinations was also sought.

\section{Experimental}

\subsection{Samples and Measurements}

All chemicals were commercially available and used without further purification.

Candida rugosa lipase (EC 3.1.1.3) (nominal activity: $920 \mathrm{Umg}_{\text {enzyme }}^{-1}$ ) was obtained from Sigma-Aldrich (St. Louis, USA). Racemic 2-bromopropanoic acid and the ionic liquids used, namely [BMIM] $\mathrm{PF}_{6}$ (1-Butyl-3methylimidazolium hexafluorophosphate), $[\mathrm{NMIM}] \mathrm{PF}_{6}$ (1-Methyl-3-nonylimidazolium hexafluorophosphate) and [BMIM] $\mathrm{BF}_{4}$ (1-Butyl-3-methylimidazolium tetrafluoroborate), were obtained from Merck KGaA (Darmstadt, Germany). Butan-1-ol as well as all the other organic solvents and salts used were manufactured by Reanal Laboratory Chemicals Ltd. (Budapest, Hungary).

In a typical experiment, $2 \mathrm{mmol}$ of racemic 2bromopropanoic acid and $12 \mathrm{mmol}$ of butan-1-ol were added to $5 \mathrm{ml}$ of solvent. The water concentration of the reaction mixture was measured using a Mettler DL35 Karl Fischer titrator. The water activity was adjusted using salts of different aw values $\left(\mathrm{LiCl}\left(a_{\mathrm{w}}=0.11\right), \mathrm{MgCl}_{2}\right.$ $\left(a_{\mathrm{w}}=0.33\right), \mathrm{NaBr}\left(a_{\mathrm{w}}=0.57\right), \mathrm{KI}\left(a_{\mathrm{w}}=0.69\right), \mathrm{KCl}$ $\left(a_{\mathrm{w}}=0.84\right)$ and $\left.\mathrm{K}_{2} \mathrm{SO}_{4}\left(a_{\mathrm{w}}=0.97\right)\right)$. The reaction was started by adding $0.1 \mathrm{~g}$ of enzyme and the closed flasks were shaken in a New Brunswick G-24 horizontal shaker incubator.

\subsection{Analysis}

The $(R)$ - and $(S)$-esters produced were analyzed by an HP 5890A GC (gas chromatograph) using a 25 m FS-LIPODEX E chiral capillary GC column from MACHEREY-NAGEL (Aachen, Germany). The samples from organic solvents were directly injected into the GC after being extracted from ionic liquids using nhexane. The activity of the lipase was characterised by the amounts of $(R)$ - and $(S)$-esters produced.

\section{Results and Analysis}

\subsection{Experiments}

To investigate the actual effect of solvents on the enzyme's activity, the same water activity should be pro- vided in the reaction media to avoid differences in enzyme activity originating from variations in water activity. By choosing the most suitable method, the application of [BMIM] $\mathrm{BF}_{4}$ must be considered, which is a polar solvent and miscible with water. The setting of the water activity with salt hydrate pairs and saturated salt solutions can be hindered as salts dissolve in ionic liquids [19]. As an alternative, the fact that the maximum enzyme activity of Candida rugosa lipase is achieved at the same water activity in any solvent was exploited [16]. According to the polarity of the solvents, the same water activity results in different water contents in various solvents, namely the reaction rate or conversion that indicate enzyme activity will be at their maxima with different water contents. An opportunity arises from the inversion of these considerations: the optimal initial water activity, required for kinetic examinations, can be set by determining the initial water content that provides the maximum reaction rate for each solvent.

Naturally, to precisely set a given water activity, the reaction rate should be measured by monitoring the water content infinite times. Instead of this, at least five different initial concentrations of water were set for each solvent. To calculate the reaction rates, the amounts of $(R)$ and $(S)$-2-Bromopropanoic acid butyl esters produced until $10 \%$ conversion was achieved or over two hours were considered. To determine the equilibrium constant necessary for calculating the enantiomeric ratio, quick reactions with $(R)$-2-bromopropanoic acid butyl ester were studied in organic solvents until the equilibrium concentration was reached. In contrast, with ionic liquids numerous reaction media had to be prepared as many samples were taken because for gas chromatography $(R)$ - and $(S)$ 2-bromopropanoic acid butyl esters had to be extracted from the ionic liquids using n-hexane and the subsequent extracts analysed. As a result, 15 reaction media were prepared simultaneously and the products extracted from them when samples were taken.

\subsection{Effect of water content}

The reaction rate altered as a function of water content according to optimum curves (Fig. 1). The highest reaction rate was obtained in n-hexane and the ionic liquid $[\mathrm{BMIM}] \mathrm{PF}_{6}$ when the concentrations of water were $0.15 \mathrm{~mol} \mathrm{dm}^{-3}\left(8.9 \times 10^{-3} \mathrm{~mol} \mathrm{~h}^{-1} \mathrm{~g}^{-1}\right)$ and $0.38 \mathrm{~mol}$ $\mathrm{dm}^{-3}$, respectively. The esterification reaction rate was very similar in toluene and $[\mathrm{BMIM}] \mathrm{PF}_{6}\left(3.2 \times 10^{-3} \mathrm{~mol}\right.$ $\mathrm{h}^{-1} \mathrm{~g}^{-1}$ and $3.0 \times 10^{-3} \mathrm{~mol} \mathrm{~h}^{-1} \mathrm{~g}^{-1}$, respectively),

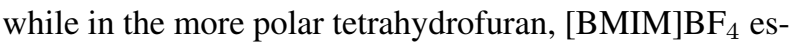
ters were produced at a very low reaction rate $\left(10^{-3} \mathrm{~mol}\right.$ $\mathrm{h}^{-1} \mathrm{~g}^{-1}$ ) which was observed to be only slightly dependent on the concentration of water.

The enantioselectivity of Candida rugosa lipase also varied as a function of water content according to optimum curves, however, was shown to be less dependent on the concentration of water than the reaction rate (Fig. 2). 


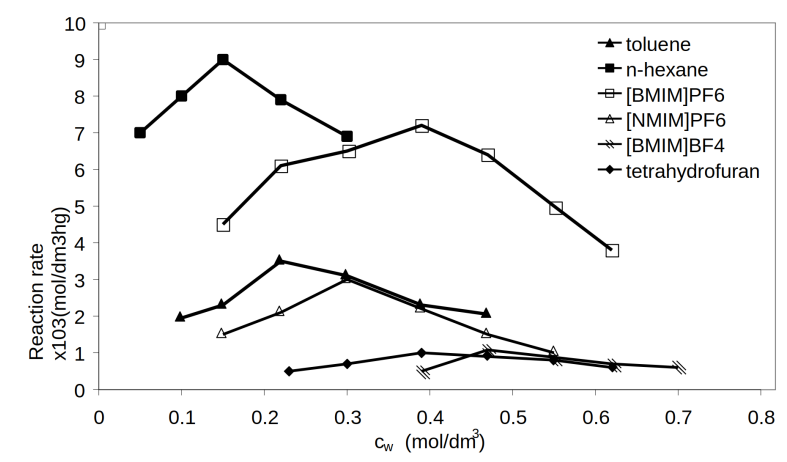

Figure 1: Dependence of the reaction rate on the initial concentration of water

The enantioselectivities in $[\mathrm{NMIM}] \mathrm{PF}_{6}$ and [BMIM] $\mathrm{PF}_{6}$ were modest (25 and 19 , respectively), while were significantly lower in the other solvents. The highest enantioselectivity $(E=10)$ was obtained in $\mathrm{n}$-hexane among other classic organic solvents.

\subsection{Discussion}

In Table 1, the concentrations of water are summarized. It is shown that the maximum reaction rate $\left(c_{\mathrm{w}}(\mathrm{conv})\right)$ or enantioselectivity $(E)\left(c_{\mathrm{w}}(\mathrm{E})\right)$ can be achieved at $30^{\circ} \mathrm{C}$ after 2 hours. The enzyme activity and enantioselectivity of Candida rugosa lipase varied according to optimum curves that plots water activity, moreover, the maximum reaction rate and enantioselectivity can be obtained at the same water activity regardless of the solvent used. Based on these observations, it is probable that the water activity will be the same in reaction media if a suitable $c_{\mathrm{w}}$ (conv) concentration of water is set in every solvent. Similarly, the water activity of reaction media will be approximately the same by setting the suitable $c_{\mathrm{W}}(E)$ concentration of water. It is possible to set approximately the same water activity in reaction media indirectly, even in the absence of salt pairs or salt hydrates.

However, it should be mentioned that the $c_{\mathrm{w}}$ values required to reach the maximum conversion or enantioselectivity are not necessarily the same. As can be observed in the case of the ionic liquid [BMIM] $\mathrm{PF}_{6}$, a maximum conversion of $29.0 \%$ was achieved when $c_{\mathrm{w}}$ (conv) $=0.38$ mol dm $\mathrm{dm}^{-3}$, while only a conversion of $26.2 \%$ was ob-

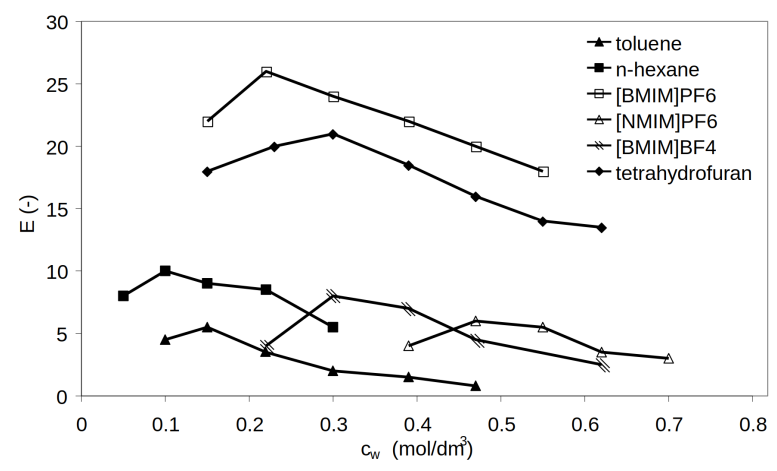

Figure 2: Dependence of the enantioselectivity on the initial concentration of water

tained when $c_{\mathrm{w}}(\mathrm{E})=0.31 \mathrm{~mol} \mathrm{\textrm {dm } ^ { - 3 }}$ required for the maximum enantioselectivity of just 20.0. Similar observations may be seen in the case of organic solvents, e.g. n-hexane in which a maximum conversion $(36.1 \%)$ was achieved when $E=8$, while maximum enantioselectivity $(E=10)$ resulted when the conversion was only $31.7 \%$. Therefore, it must be decided whether reaching the maximum conversion or maximum enantioselectivity is the aim. The determination of the maximum conversion as a function of the required enantioselectivity will be the subject of future research.

\section{Conclusion}

In this study, it has been proven by the esterification of 2-bromopropanoic acid in the presence of Candida rugosa lipase that during reactions conducted in such nonconventional media, the determination of the optimal water content can be significantly simplified by setting the optimal concentration of water instead of the water activity, which is difficult to accomplish. For this purpose, the initial water content required to achieve the maximum reaction rate must be determined. As the water contents needed to achieve the maximum conversion or maximum enantioselectivity are usually different, further optimization tasks are necessary.

\section{Acknowledgement}

The financial support of Széchenyi 2020 under the project EFOP-3.6.1-16-2016-00015 is acknowledged.

Table 1: Conversion and enantioselectivity during the enantioselective esterification reaction at the optimum $c_{\mathrm{W}}(\mathrm{conv})$ and $c_{\mathrm{w}}(\mathrm{E})$ values in different solvents $\left(T=30^{\circ} \mathrm{C}, t=2 \mathrm{~h}\right)$.

\begin{tabular}{|c|c|c|c|c|c|c|c|}
\hline Solvent & $\begin{array}{c}\log P \\
-\end{array}$ & $\begin{array}{l}c_{\mathrm{w}}(\text { conv }) \\
\mathrm{mol} \mathrm{dm}^{-3}\end{array}$ & $\begin{array}{c}\text { Conversion } \\
\%\end{array}$ & $\begin{array}{c}E \\
-\end{array}$ & $\begin{array}{c}c_{\mathrm{W}}(E) \\
\mathrm{mol} \mathrm{dm}^{-3}\end{array}$ & $\begin{array}{c}\text { Conversion } \\
\%\end{array}$ & $\begin{array}{c}E \\
-\end{array}$ \\
\hline$[\mathrm{BMIM}] \mathrm{BF}_{4}$ & -2.44 & 0.54 & 4.6 & 5 & 0.46 & 4.0 & 6 \\
\hline$[\mathrm{BMIM}] \mathrm{PF}_{6}$ & -2.38 & 0.38 & 29.0 & 18 & 0.31 & 26.2 & 20 \\
\hline$\left[\mathrm{NMIM} \mathrm{PF}_{6}\right.$ & -2.19 & 0.31 & 13.4 & 24 & 0.23 & 8.9 & 25 \\
\hline Tetrahydrofuran & 0.50 & 0.38 & 4.3 & 4 & 0.31 & 3.2 & 5 \\
\hline Toluene & 2.50 & 0.23 & 13.9 & 3 & 0.15 & 10.1 & 5 \\
\hline n-Hexane & 3.50 & 0.15 & 36.1 & 8 & 0.08 & 31.7 & 10 \\
\hline
\end{tabular}




\section{REFERENCES}

[1] Carrea, G.; Riva, S.: Organic synthesis with enzymes in non-aqueous media (Wiley-VCH Verlag GmbH \& Co. KGaA, Weinheim, Germany) 2008, pp. 169-190 ISBN: 978-3-527-31846-9

[2] Bommarius, A. S.; Riebel, B. R.: Biocatalysis (Wiley-VCH Verlag $\mathrm{GmbH} \& \mathrm{Co}$. KGaA, Weinheim, Germany) 2004, pp. 339-372 DOI: 10.1002/3527602364.ch12

[3] Gholivand, S.; Lasekan, O.; Tan, C. P.; Abas, F.; Wei, L. S.: Optimization of enzymatic esterification of dihydrocaffeic acid with hexanol in ionic liquid using response surface methodology, Chem. Cent. J., 2017, 11(44), 1-10 DOI: 10.1186/s13065-017-0276-2

[4] Ghaffari-Moghaddam, M.; Eslahi, H.; Aydin, Y. A.; Saloglu, D.: Enzymatic processes in alternative reaction media: a mini review, J. Biol. Met., 2015, 2(3), 25-35 DOI: 10.14440/jbm.2015.60

[5] Hobbs, H. R.; Thomas, N. R.: Biocatalysis in supercritical fluids, in fluorous solvents, and under solvent-free conditions, Chem. Rev., 2007, 107(6), 2786-2820 DOI: 10.1021/cr0683820

[6] Naushad, M.; ALOthman, Z. A.; Khan, A. B.; Ali, M.: Effect of ionic liquid on activity, stability, and structure of enzymes: A review, Int. J. Biol. Macromol., 2012, 51(4), 555-560 DOI: 10.1016/j.ijbiomac.2012.06.020

[7] Ulbert, O.; Fráter, T.; Bélafi-Bakó, K.; Gubicza, L.: Enhanced enantioselectivity of Candida rugosa lipase in ionic liquids as compared to organic solvents, J. Mol. Catal. B: Enzym., 2004, 31(1-3), 3945 DOI: $10.1016 /$ j.molcatb.2004.07.003

[8] Wu, B.-P.; Wen, Q.; Xu, H.; Yang, Z.: Insights into the impact of deep eutectic solvents on horseradish peroxidase: Activity, stability and structure, $J$. Mol. Catal. B: Enzym., 2014, 101, 101-107 DOI: 10.1016/j.molcatb.2014.01.001

[9] Ghaffari-Moghaddam, M.; Ahmad, F. B. H.; Basri, M.; Abdul Rahman, M. B.: Lipase-catalyzed esterification of betulinic acid using phthalic anhydride in organic solvent media: Study of reaction parameters, J. Appl. Sci., 2010, 10(4), 337-342 DOI: 10.3923/jas.2010.337.342

[10] Peres, C.; Gomes da Silva, M. D. R.; Barreiros, S.: Water activity effects on geranyl acetate synthesis catalyzed by Novozym in supercritical ethane and in supercritical carbon dioxide, J. Agric. Food Chem., 2003, 51(7), 1884-1888 DOI: 10.1021/jf026071u
[11] Svensson, I.; Wehtje, E.; Adlercreutz, P.; Mattiasson, B.: Effects of water activity on reaction rates and equilibrium positions in enzymatic esterifications, Biotechnol. Bioeng., 1994, 44(5), 549-556 DOI: 10.1002/bit.260440502

[12] Páez, B. C.; Medina, A. R.; Rubio, F. C.; Moreno, P. G.; Grima, E. M.: Modeling the effect of free water on enzyme activity in immobilized lipase-catalyzed reactions in organic solvents, Enzyme Microb. Technol., 2003, 33(6), 845-853 DOI: 10.1016/S01410229(03)00219-9

[13] Kwon, C. H.; Lee, J. H.; Kim, S. W.; Kang, J. W.: Lipase-catalyzed Esterification of (S)-naproxen ethyl ester in supercritical carbon dioxide, $\mathrm{J} . \mathrm{Mi}$ crobiol. Biotechnol., 2009, 19(12), 1596-1602 DOI: 10.4014/jmb.0905.05051

[14] Gubicza, L.; Bélafi-Bakó, K.; Fehér, E.; Fráter, T.: Waste-free process for continuous flow enzymatic esterification using a double pervaporation system, Green Chem., 2008, 10(12), 1284-1287 DOI: 10.1039/B810009H

[15] Benedict, D. J.; Parulekar, S. J.; Tsai, S.-P.: Pervaporation-assisted esterification of lactic and succinic acids with downstream ester recovery, J. Membr. Sci., 2006, 281(1-2), 435-445 DOI: 10.1016/j.memsci.2006.04.012

[16] Fontes, N.; Harper, N.; Halling, P. J.; Barreiros, S.: Salt hydrates for in situ water control have acid-base effects on enzymes in nonaqueous media, Biotechnol. Bioeng., 2003, 82(7), 802-808 DOI: 10.1002/bit.10627

[17] Márkus, Zs.; Bélafi-Bakó, K.; Tóth, G.; Nemestóthy, N.; Gubicza, L.: Effect of chain length and order of the alcohol on enzyme activity during enzymatic esterification in organic media, Hung. J. Ind. Chem., 2017, 45(2), 35-39 DOI: 10.1515/hjic-2017-0018

[18] Robb, D. A.; Yang, Z.; Halling, P. J.: The use of salt hydrates as water buffers to control enzyme activity in organic solvents, Biocatalysis, 2009, 9(1-4), 277283 DOI: 10.3109/10242429408992127

[19] Eckstein, M.; Wasserscheid, P.; Kragl, U.: Enhanced enantioselectivity of lipase from Pseudomonas sp. at high temperatures and fixed water activity in the ionic liquid, 1-butyl-3methylimidazolium bis[(trifluoromethyl)sulfonyl]amide, Biotechnol. Lett., 2002, 24(10), 763-767 DOI: 10.1023/A:1015563801977 